\title{
Prevalência dos Sinais e Sintomas Osteomoleculares em cirurgiões Dentistas
}

\author{
Livia Maria dos Santos Landim ${ }^{1}$; Cristiane Marinho Uchôa Lopes ${ }^{2}$; Gledson Fernandes de Sousa ${ }^{3}$; Sidney Medeiros de
} Oliveira $^{4}$; Anny Caroline Costa Vieira ${ }^{5}$; Hermes Melo Teixeira Batista ${ }^{6}$; Elisian Macedo Fechine ${ }^{7}$

Resumo: O DORT é definido pela Previdência Social (1998) como um conjunto de afecções relacionadas com as atividades laborativas na qual acometem músculos, tendões, fáscias musculares, ligamentos, articulações, nervos e vasos sanguíneos. O aparecimento dos sintomas osteomusculares vem aumentando mundialmente e, no Brasil, começou a adquirir expressão em número e relevância social, a partir da década de 80, tornando um grave problema de saúde pública e social em função da sua abrangência e magnitude. Os cirurgiões-dentistas são constantemente submetidos a fatores de riscos para o aparecimento de lesão relacionado ao trabalho, o que torna relevante a realização desta pesquisa. $\mathrm{O}$ objetivo deste trabalho é verificar a prevalência dos sinais e sintomas osteomusculares em cirurgiões-dentistas da cidade de Barbalha, Ceará. A metodologia foi realizada pelo estudo quantitativo. A população analisada foi composta por cirurgiões-dentistas $(n=25)$, atuantes na cidade de Barbalha e para a coleta foi aplicado o questionário Nórdico para sintomas osteomusculares e outro para a verificação do grau de conhecimento do profissional em relação ao DORT, como também, verificar os principais procedimentos clínicos dos cirurgiões-dentistas que produzem algias. No resultado e na discussão, pode-se observar um dado preocupante encontrado na pesquisa que diz respeito que estes trabalham mais de um turno e que $40 \%$ dos entrevistados apresentavam sinais e sintomas osteomusculares, com freqüência nos membros superiores e $36 \%$ em coluna dorsal, lombar e membros inferiores. O procedimento com maior índice de algia é a extração. Dentre as patologias, a tendinite foi a mais diagnosticada. Conclui-se de acordo com os resultados, que os cirurgiões-dentistas atuantes na cidade de Barbalha estão expostos a fatores de riscos para o aparecimento de DORT.

Palavras-chave: Cirurgiões-Dentistas; DORT; Fisioterapia.

\section{Prevalence of Signs and Symptoms of Musculoskeletal Disorders in Surgeons Dentists}

Abstract: MSDs is defined by Social Security (1998) as a set of conditions related to work activities in which affect muscles, tendons, muscle fascia, ligaments, joints, nerves and blood vessels. The appearance of musculoskeletal symptoms is increasing worldwide and in Brazil, began to acquire expression and social relevance in the 80 's, becoming a serious problem of social and public health due to its scope and magnitude.

\footnotetext{
${ }^{1}$ Graduação em Fisioterapia pela Faculdade Leão Sampaio . Especialista em UTI Neonatal e Pediatrica pela Faculdade Redentor (RJ). E-mail: linlandim@hotmail.com;

${ }^{2}$ Graduação em Fisioterapia pela Faculdade Integrada do Ceará, Pós- graduação em Fisioterapia em Terapia Manual e Postural pelo Centro Universitário de Maringá - CESUMAR, Formação em Osteopatia pela Escola Brasileira de Osteopatia e Terapia Manual (EBOM), Especialista em Saúde Coletiva pela Universidade Federal de São Paulo (UNIFESP), Especialista em Docência do Ensino Superior pela Faculdade Leão Sampaio. Pós-graduada em Fisiologia do Exercício e Grupos Especiais pela Faculdade Leão Sampaio (FALS) e Mestre em Saúde Coletiva pela Universidade de Fortaleza (UNIFOR). Docente da Faculdade Leão Sampaio e da Estácio/FMJ. ;

${ }^{3}$ Graduação em Fisioterapia pela Faculdade Leão Sampaio (2005). Atualmente é fisioterapeuta administrador - Clinicenter Cariri, fisioterapeuta - Nasf - Município Barbalha e fisioterapeuta - Cliniafagu - Juazeiro do Norte - CE;

${ }^{4}$ Graduação em Educação Física pela Universidade Federal de Pernambuco (1983). Doutorando em Ciências da Saúde pela Faculdade de Medicina do ABC - São Paulo. Pós-Graduação em Docência do Ensino Superior - Faculdades Integradas de Patos - PB. Professor de Educação Física do Município de Caririaçu-CE/ 2012. Professor de Musculação, Futsal e natação do SESC- CE. E-mail: meolli@hotmail.com;

${ }^{5}$ Especialista Politicas Publica em Saúde Coletiva pela Universidade Regional do Cariri ; Fisioterapeuta graduada pela Faculdade de Ciências Aplicadas Doutor Leão Sampaio; aluna do curso de Pós-Graduação em Fisioterapia em Terapia Intensiva e Suporte Ventilatório pela Faculdade Maurício de Nassal. E-mail: anny_carol_15@ @otmail.com;

${ }^{6}$ Graduação em Medicina pela Universidade Federal do Ceará. Médico do Hospital Regional do Cariri e Professor da Faculdade de Medicina de Juazeiro do Norte- Estácio. Título de Especialista em Anestesiologia pela Sociedade Brasileira de Anestesiologia. Mestrado em Ciências da Saúde pela Faculdade de Medicina do ABC -SP. Doutorado em andamento pela Faculdade de Medicina do ABC.Pós graduação em Preceptoria em Residência Médica pelo Hospital Sírio Libanês em andamento. Membro afiliado da European Society of Anesthesiology. E-mail: hermesmelo@oi.com.br.;

${ }^{7}$ Fisioterapeuta pela Universidade de Fortaleza - UNIFOR. Acadêmica de medicina da Faculdade de Medicina de Juazeiro do Norte - Ceará. Contato: elisian_fechine@hotmail.com.
} 
The dentists are constantly subjected to risk factors for the onset of work-related injury, which is relevant to this research. The objective of this study is to determine the prevalence of musculoskeletal signs and symptoms in dentists in the city of Barbalha, Ceará. The methodology was performed by quantitative study. The study sample consisted of dentists $(n=25)$, working in the city of Barbalha and for aquisition was applied the Nordic questionnaire for musculoskeletal symptoms and another for verification of professional knowledge regarding MSDs, but also, check the main clinical procedures of dentists that produce pain. In the results and discussion, one can observe a worrying data found in research that they work more than one shift and $40 \%$ of respondents had musculoskeletal signs and symptoms, often in the upper limbs and $36 \%$ in the dorsal column, lumbar and lower limbs. The procedure with the higher pain incidence is extraction. Among the diseases, tendinitis was the most diagnosed. It is concluded according to the results, that the dentists working in the city of Barbalha are exposed to risk factors for the onset of MSDs.

Keywords: Dentists; MSDs; Physiotherapy.

\section{Introdução}

A Odontologia é uma profissão da área de saúde com uma ampla gama de possibilidades de atuação, desde o consultório odontológico até a administração, passando pela docência, pesquisa e, até na área de perícia civil e criminal. No entanto, ocorre uma grande concorrência no mercado de trabalho, sendo submetida a uma carga de estresse de diversos tipos.

No consultório odontológico, o cirurgião-dentista (CD) está exposto a diversas lesões, especialmente, às relacionadas aos movimentos repetitivos, carga emocional e às posturas assumidas durante o exercício profissional.

O distúrbio osteomuscular relacionado ao trabalho (DORT) atinge várias áreas de atuação profissional como, por exemplo: dentistas, fisioterapeutas, motoristas, professores, escriturários, digitadores, entre outros. Em relação aos cirurgiões-dentistas, o DORT representa uma importante causa de afastamento funcional. Além disso, deve-se verificar que este profissional está exposto frequentemente a sobrecarga emocional relacionado ao número de pacientes, a carga horária extensa, ao ambiente de trabalho (inclusive iluminação), ruídos, ambiente fechado, ventilação e até mesmo ao baixo rendimento financeiro da profissão.

Outro fator determinante de lesões é a postura adotada durante a atividade profissional, que inclui as posições sentadas e ortostáticas, bem como, a dinâmica dos movimentos executados, de rotações e inclinações duradoras, amplas e repetitivas. Os DORT's que estão frequentemente associados ao exercício da Odontologia são: cervicobraquialgia, bursite, síndrome do desfiladeiro torácico, epicondilite lateral, síndrome do túnel do carpo, tenossinovite de Quervain (LAZIER et al. apud ARAUJO; PAULO 2003)

O DORT é definido pela Previdência Social (1998) como um conjunto de afecções relacionadas com as atividades laborativas na qual acometem músculos, tendões, fáscias musculares, ligamentos, articulações, nervos e vasos sanguíneos. 
O aparecimento dos sintomas osteomusculares vem aumentando mundialmente e, no Brasil, começou a adquirir expressão, em número e relevância social, a partir da década de 80 , tornando um grave problema de saúde pública e social, em função da sua abrangência e magnitude. Sendo que os DORT's representam um dos grupos de doenças ocupacionais mais polêmicos no Brasil e em outros países, e vem assumindo um caráter epidêmico.

A cidade de Barbalha que está situada na região sul do Ceará é um dos municípios mais antigos da região do Cariri, com aproximadamente vinte e cinco cirurgiões-dentistas, atuantes tanto no setor público como privado (CRO-CE, 2009).

Nesse contexto, diante da realidade dos cirurgiões-dentistas surgiu o interesse em realizar este trabalho a partir da observação durante o acompanhamento de cirurgiões-dentistas e da necessidade de conscientizar estes profissionais quanto aos aspectos ergonômicos, para prevenir o surgimento de lesões e de sintomatologias relacionadas.

Busca-se contribuir com dados para a atuação da Fisioterapia Preventiva não só cirurgiõesdentistas da cidade de Barbalha, Ceará como para a atuação fisioterápica junto com os demais cirurgiões-dentistas de outras regiões.

O objetivo do presente estudo foi Verificar a prevalência dos sinais e sintomas osteomusculares em cirurgiões-dentistas da cidade de Barbalha, Ceará. Neste sentido, foi necessário também: a) Traçar os procedimentos clínicos dos cirurgiões-dentistas que produzem algias; b) Analisar a prevalência de sinais e sintomas relacionados ao DORT; c) Verificar a presença do conhecimento entre os profissionais estudados acerca das atividades ocupacionais e o acometimento do DORT; e, d) Identificar as estratégias preventivas realizadas em relação DORT.

\section{Metodologia}

A pesquisa de campo, do tipo epidemiológico, com metodologia exploratória, transversal e descritiva baseado em estratégias de análise quantitativa. De acordo com Richardson et al. apud Marconi; Lakatos (2009), “ a análise quantitativa, se caracteriza pelo emprego da quantificação tanto nas modalidades de coleta de informações quanto no tratamento delas por meio de técnicas estatísticas, sendo utilizados questionários, entrevistas e observações. Com isso podemos dizer que o método quantitativo é constituído em quantificar dados através de informações coletados."

O estudo foi desenvolvido na cidade de Barbalha, Ceará, nos consultórios odontológicos particulares e da rede pública. A amostra foi composta por cirurgiões-dentistas $(n=25)$ atuantes nas cidades de Barbalha, Ceará, cadastrados no Conselho Regional de Odontologia (CRO) sendo constituída por aqueles que atendam aos critérios de inclusão e não se enquadrem nos critérios de exclusão. 
Id on Line Revista Multidisciplinar e de Psicologia

Id on Line Multidisciplinary and Psychology Journal

Os critérios de inclusão adotados para a amostra foram: cirurgiões-dentistas de ambos os sexos atuantes na cidade de Barbalha; período mínimo de atuação profissional de dois anos; que atendam pacientes com carga horária de trabalho superior a seis horas; aceitação voluntária em participar do estudo, confirmada mediante a assinatura de um Termo de Consentimento Livre e Esclarecido (APÊNDICE A). Os indivíduos que apresentaram deficiência visual incapacitantes não foram incluídos no estudo.

\section{Instrumento de Coleta de Dados}

A pesquisa foi realizada com um instrumento adaptado do questionário nórdico para sintomas osteomusculares (APÊNDICE B) para a verificação da prevalência dos sinais e sintomas osteomusculares em cirurgiões-dentistas da cidade de Barbalha, Ceará. De acordo com Kilbom apud Sousa (2009) o questionário foi desenvolvido para facilitar e padronizar a mensuração de relatos de sintomas osteomusculares. Sendo elaborado pelo Conselho Nacional para Segurança e Saúde Ocupacional em Solna. Deste então vem sendo utilizado para registrar e analisar as informações acerca do DORT, visto que o questionário não é indicado como base para diagnóstico clínico, mas sim para a identificação de distúrbios osteomusculares e, conseqüentemente contribuindo para o diagnóstico do ambiente ou do posto de trabalho. Um questionário específico (APÊNDICE C) para a verificação do grau de conhecimento do profissional em relação ao DORT, como também verificar os principais procedimentos dos cirurgiões-dentistas que produzem algias, e os principais sinais e sintomas relacionados ao DORT.

\section{Estratégia para Análise de Dados e Apresentação dos Resultados}

Os dados foram analisados a partir da estatística descritiva através do uso de um software Excel Office 2007. Após a tabulação dos dados, os mesmos foram apresentados por meio de gráficos e tabelas.

\section{Aspectos Éticos}

Cada participante do estudo assinou um Termo de Consentimento Livre e Esclarecido (APÊNDICE A) em atendimento ao artigo IV, parágrafo $3^{\circ}$ da resolução 196/96 do CNS/NS, que trata da pesquisa envolvendo seres humanos. Esse projeto foi submetido ao Comitê de Ética e Pesquisa da Faculdade de Medicina de Juazeiro do Norte (FMJ). 


\section{A Odontologia enquanto profissão}

A Odontologia é uma profissão da área de saúde, que tem como meta o trabalho envolvendo a saúde geral do paciente, higiene bucal, trabalhos de prevenções, diagnósticos e de tratamentos das diversas anomalias dentárias, como também, das principais patologias que envolvem os dentes, a boca e as estruturas maxilares e de seus devidos prognósticos (CRO-CE, 2009).

Segundo o Código de Ética (2006) os direitos dos profissionais inscritos, estão às atribuições nas específicas áreas: diagnóstico, planejamento e execução de tratamentos, com liberdades de convicções e nos limites de suas atribuições, observado o estado atual da ciência e sua dignidade profissional.

Os cirurgiões-dentistas vêm atuando diariamente com os propósitos de trabalho em relação ao estudo, a interpretação e acima de tudo nas soluções de diversos problemas bucais que atingem a população em geral (Silva et al. apud Garrafa ,1986).

Segundo Oliveira e Oliveira Junior (1999) o profissional trabalha em regime liberal, ou seja, suas horas de trabalho estão diretamente relacionadas aos atendimentos clínicos prestados nas clínicas das redes públicas e particulares.

Ao longo dos anos vários estudos comprovaram que, os profissionais da área de saúde adoeciam e tinham crises de estresses relacionados ao ritmo de trabalho, destacando o cirurgiãodentista, além disso, o mercado de trabalho vem passando por várias reformas ocasionando consequiências entre os CD’s e sua profissão. (NUNES; FREIRE, 2006).

Segundo Nunes e Freire (2006) vários pesquisadores estudaram a saúde dos cirurgiõesdentistas em alguns países, nos quais concluíram que umas das causas de afastamento da profissão e de origem ergonômica, entre esses países o Brasil segue o mesmo padrão.

Em relação aos principais achados ergonômicos, os CD's estão predispostos às doenças ocupacionais, principalmente as do sistema músculo- esquelético.

Além da fadiga, há o aumento na tensão muscular, aumento dos batimentos cardíacos, mudanças químicas no sangue, formação de toxinas, aumento do nível de envelhecimento, dores de cabeça, insensibilidade da retina e até perda da visão. $\mathrm{O}$ estresse que decorre desses problemas, se reflete no organismo como um todo, a produtividade e a qualidade do trabalho caem consideravelmente (GARBIN et al., 2007, p.29) 
Segundo Garbin et al. (2007) nos consultórios odontológicos o profissional deve manter uma boa iluminação, pois com a utilização das técnicas, diminuirá a fadiga e as deficiências visuais que com o passar do tempo, atrapalhará o rendimento e a qualidade do serviço.

No desempenho da prática odontológica, o ambiente físico de trabalho (iluminação, temperatura, ruído e cores), aliado às características ergonômicas dos equipamentos e ao manejo adequado do pessoal auxiliar permitirá ao profissional uma produtividade cada vez mais expressiva (GARBIN et al., 2007, p.29).

Podem existir também alterações auditivas, pois durante a rotina de trabalho passa muito tempo exposto a ruídos de diversas qualidades e de altas freqüências (FIORINI apud LACERDA et al., 2002).

No estudo de Saquy apud Lacerda et al. (2002) entre os ruídos que mais incomoda os CD’s estão os ruídos dos compressores de ar, turbinas de alta frequiência, sugadores da saliva, além do som do ambiente e dos ruídos externos, ocasionando até $60 \%$ de redução na produtividade.

Diariamente, o profissional de Odontologia vem sobrecarregando as suas estruturas anatômicas do esqueleto axial e apendicular por movimentos repetitivos e carga excessiva.

\section{Anatomia do Esqueleto Axial e Apendicular}

\section{Coluna Vertebral}

A coluna vertebral é composta de uma série de ossos denominados vértebras, como mostra a figura 01. A coluna vertebral funciona como uma haste forte e flexível, que pode girar e mover-se anteriormente, posteriormente e lateralmente. Encerra e protege a medula espinhal, sustenta a cabeça e ponto de fixação para as costelas, o cíngulo do membro inferior e os músculos do dorso (TORTORA, 2006).

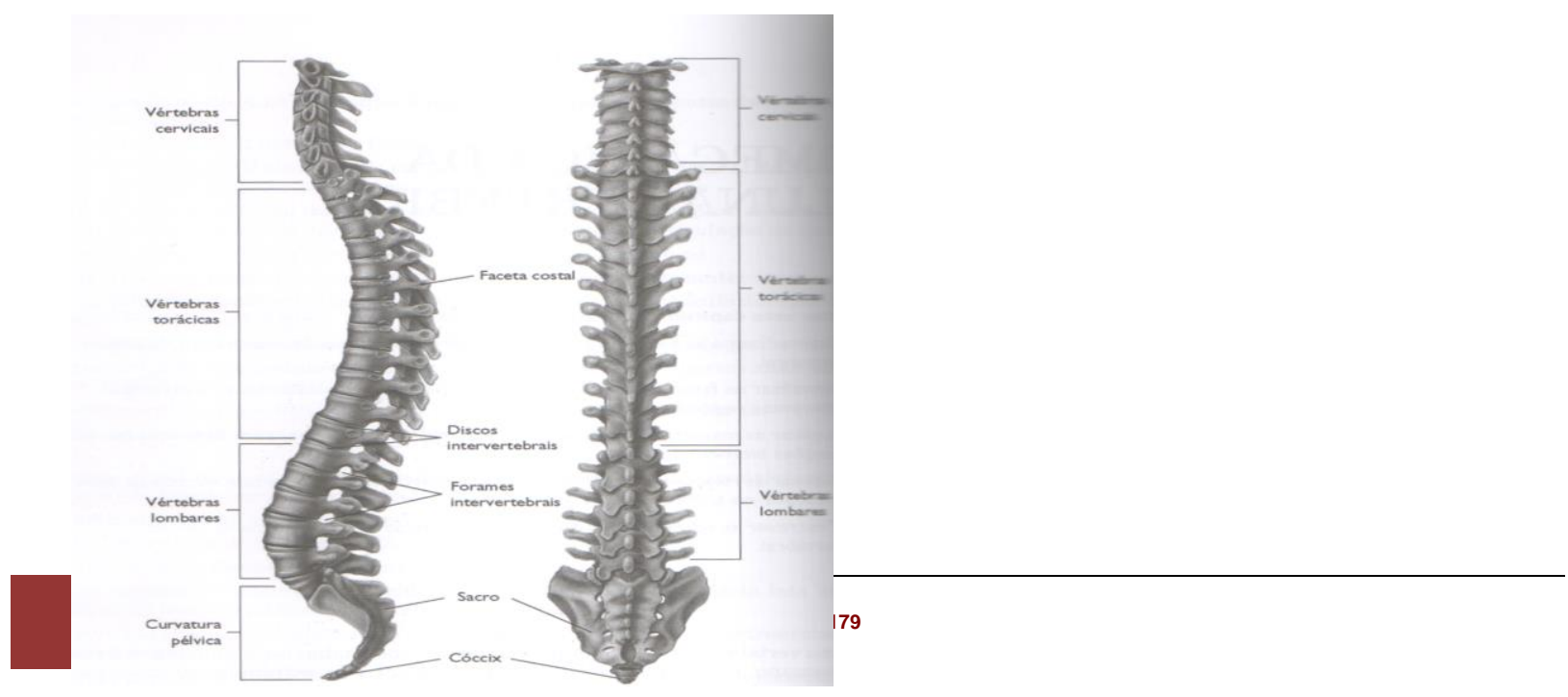


Figura 01: Anatomia da coluna vertebral. (HALL, 2005, p.264).

As vértebras adjacentes são separadas por uma estrutura fibrocartilosa interposta que atua como coxins, que são chamados, discos intervertebrais, caso ocorra degenerações desses discos, por qualquer força de compressão súbita pode espremer a massa viscosa do interior do disco para fora, por alguma ruptura dos anéis fibrosos, exercendo pressão na própria medula ou nos nervos eferentes (KROEMER; GRANDJEAN, 2005).

Nas atividades diárias, os dentistas sofrem grande desgaste da coluna vertebral, pois os mesmos realizam vários movimentos de duração ampla e repetitiva como a rotação e inclinação de tronco, fazendo com que os discos se desloquem anteriormente, posteriormente e lateralmente, de acordo com a figura 02 .

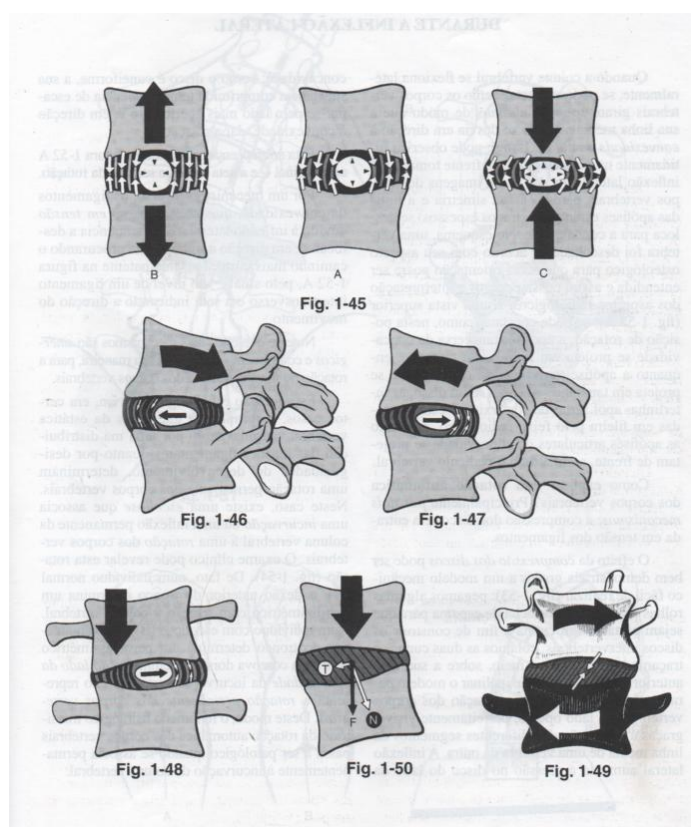

Figura 02: Deslocamento dos discos intervertebrais durante os movimentos da coluna vertebral (KAPANDJI, 2000, p.43).

\section{Membro Superior}

É dividido basicamente em quatro estruturas adequadas para as realizações de suas funções, entre elas: cíngulo do membro superior, braço, antebraço e mão; tendo como característica principal o domínio de mobilização, habilidade para agarrar e manipular objeto (MOORE, 2004). 
Id on Line Revista Multidisciplinar e de Psicologia

Id on Line Multidisciplinary and Psychology Journal

A principal nutrição nervosa do membro superior é o plexo braquial (figura 03) no qual se encontra entre a união dos ramos primários dos nervos $\mathrm{C}_{5}$ até $\mathrm{C}_{8}$ e pela maior parte do ramo anterior do nervo $T_{1}$, onde esta união forma as raízes nervosas do plexo braquial, que estão localizadas no trígono posterior do pescoço. Entre os ramos mais importantes encontrados no plexo braquial estão os nervos: mediano, ulnar, radial, axilar e musculocutâneo (TORTORA, 2006).

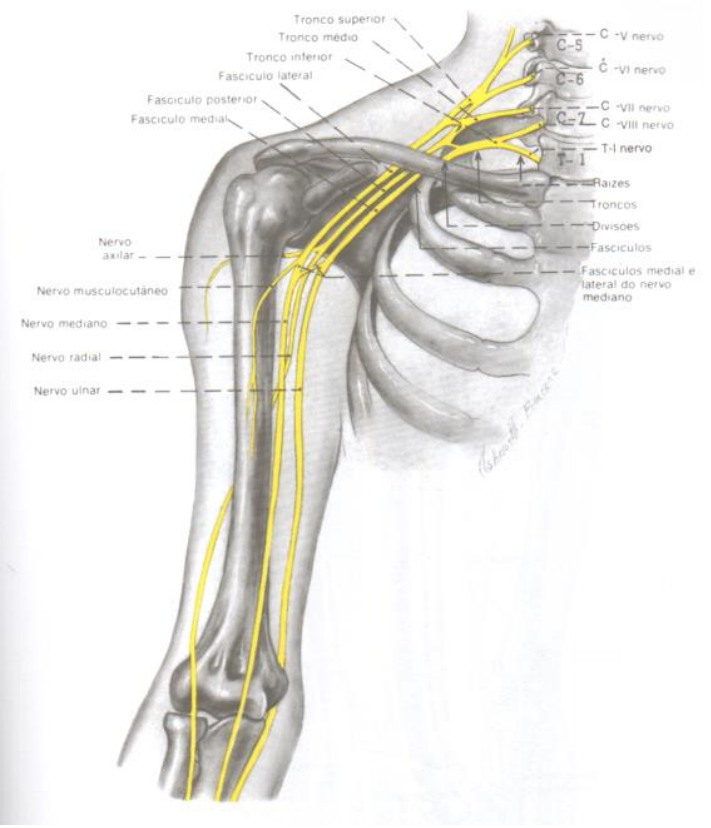

Figura 03: Anatomia do plexo braquial. Inervação do membro superior. (JACOB et al., 1982, p.239).

Durante a atividade odontológica os cirurgiões-dentistas utilizam os movimentos de abdução, rotação interna, supinação de antebraço, entre outros. O profissional após um longo período com o membro superior elevado, ocorre uma compressão dos músculos escalenos, prejudicando as inervações ao nível do plexo braquial, causando parestesia e sensação dolorosa no membro superior.

Os cirurgiões-dentistas na sua jornada de trabalho encontram-se com braço em rotação interna, o antebraço em pronação e a mão em flexão. Os movimentos finos são os de pinça fina e pinça grossa, devido a utilização de forma exagerada dessas estruturas, ocorrendo uma sobrecarga mecânica no membro superior utilizado.

\section{Membro Inferior}

O membro inferior é caracterizado pela função de sustentação do peso corporal, como também, da locomoção (HALL, 2005). 
Id on Line Revista Multidisciplinar e de Psicologia

Id on Line Multidisciplinary and Psychology Journal

Devido aos períodos prolongados na postura sentada em uma cadeira, que muitas vezes não é ergonômica, o dentista se adapta às posturas erradas, sobrecarregando o membro inferior por movimentos de flexão plantar e dorsoflexão, além de deixar o membro exposto às vibrações decorrentes do pedal, que é utilizado para acionamento da caneta de alta e baixa rotação, o rodapé.

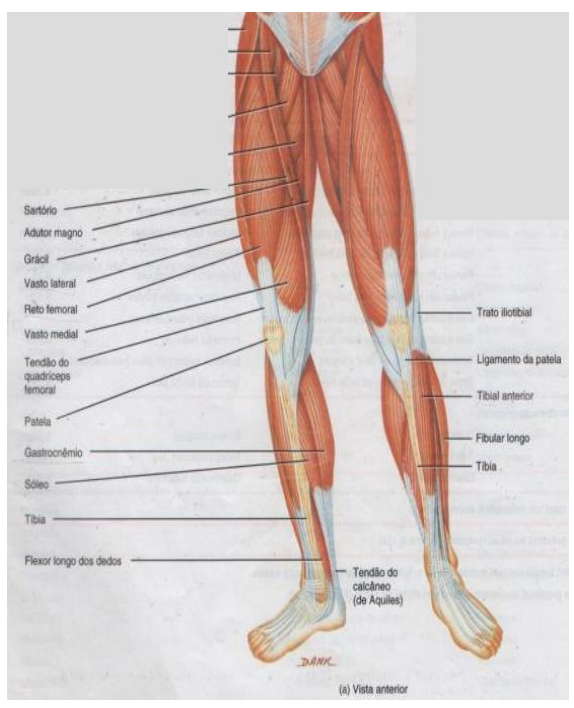

Vista anterior

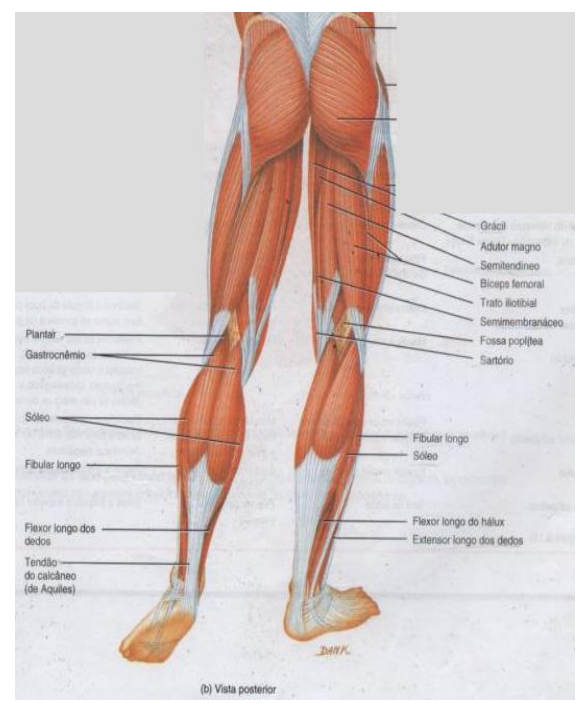

Vista posterior
Figura 04: Anatomia do membro inferior.

(TORTORA;

GRADOWSKI, 2006,

P.194-195).

Ergonomia e a Odontologia

\section{Ergonomia do Posto de Trabalho}

Ergonomia palavra essa derivada da língua grega (ergo: trabalho e nomos: leis, ou seja, leis que regem o trabalho), vários autores propuseram definições diferentes para a ergonomia, mas atualmente, a definição mais encontrada na literatura é a de Wisner (1987) que confere a ergonomia o significado de um conjunto de conhecimentos científicos relacionados ao homem e às suas necessidades nas concepções de máquinas, instrumentos e dispositivos, que venham priorizar o máximo de bem-estar, segurança e eficiência (DELIBERATO, 2002).

Podemos considerar que a ergonomia busca uma visão entre as condições do trabalho e uma tríade formada pelo bem-estar, segurança e a condição do trabalhador em sua situação de trabalho, sendo diferenciada das demais áreas de conhecimento pela sua característica interdisciplinar e pela sua natureza aplicada. A característica interdisciplinar é referida pela base múltipla de conhecimento. A natureza aplicada se configura na adaptação do posto de trabalho e dos níveis ambiências em relação às características fisiológicas e psicológicas do trabalhador (DELIBERATO, 2002). 
Segundo Pequini (2005) entre os aspectos estudados na ergonomia, incluem a postura e os seus diversos movimentos corporais como o sentar, empurrar, ficar de pé, rodar, puxar e levantar peso; os fatores ambientais, como o clima, ruídos, vibrações, iluminação, agentes químicos e as informações visuais e auditivas. A conjugação adequada desses fatores permite projetar ambientes seguros, saudáveis, confortáveis e eficientes, tanto no trabalho quanto na vida cotidiana.

Entre as diversas situações que acompanha o trabalhador em seu dia-a-dia e no seu planejamento de trabalho, a ergonomia tem como foco primordial o ser humano (GARBIN et al., 2008).

A ergonomia visa a ação que se propõe na transformação do trabalhador no seu campo de trabalho, essa transformação deve ser realizada para obter as devidas contribuições. Dentre elas, a prevenção da saúde dos trabalhadores na sua situação atual de trabalho, como também, obter transformações no lado coletivo, almejando os objetivos econômicos que muitas vezes são requeridos pela empresa atual de trabalho (KERGUELEN et al., 2001).

A ergonomia propriamente dita apóia-se em quatro pilares: o ambiente na qual o individuo está inserido, nas ferramentas de trabalho por ele utilizadas, no desenvolvimento do trabalho para realização da atividade e nos elementos que estão diretamente ligados ao próprio individuo (BARBOSA, 2009).

Possui visão holística, em se tratando das diversas considerações, que envolve os principais aspectos físicos, sociais, cognitivos, organizacionais e ambientais. Quando se trata da ergonomia física, parte dos conhecimentos é voltada para a anatomia, antropométria, fisiologia e a biomecânica, dando ênfase a postura utilizada durante o trabalho, os materiais utilizados, movimentos repetitivos, desordens músculos-esqueléticas, segurança e a saúde. Na cognitiva está diretamente relacionada aos processos mentais como: percepção, memória, raciocínio e resposta motora. A organizacional aborda a questão dos sistemas sócio-técnicos onde inclui a estrutura organizacional, políticas e as de processos (BARBOSA, 2009).

A ergonomia na prática odontológica visa o objetivo em racionalizar, os principais movimentos inadequados no campo da Odontologia, ou seja, tem como meta a não produção de movimentos, posturas inadequadas e anti-anatômicas, fazendo com que o profissional possa produzir mais e melhor, evitando a fadiga, o desgaste físico e mental desnecessário, obtendo assim, um maior rendimento financeiro, como também, ofertando ao paciente uma maior grau de segurança e conforto (BARROS apud BARBOSA et al., 2004 ).

Com isso na prática Odontológica a ergonomia atua simplificando o trabalho, tendo como meta a prevenção do estresse tanto físico como mental, proporcionando assim um maior conforto para o profissional (RABELO et al.; apud BARBOSA et al., 2004). 
As primeiras contribuições da ergonomia no campo da Odontologia destinaram-se a melhorar as condições de trabalho dos CD's e aperfeiçoando as ferramentas, instrumentos e mobiliário utilizado por esses profissionais (RASIA, 2004, p.22).

\section{Fisioterapia Preventiva}

Os atendimentos odontológicos devem ser planejados na forma de estratégicas, onde o profissional venha a obter suas metas e seu desempenho social. Algumas regras foram solicitadas para que a ergonomia organize a biomecânica do trabalhador no seu campo de trabalho, entre elas: o corpo tem que trabalhar de forma desejável, utilizando posturas adequadas de acordo com a exigência do trabalho, as bancadas deverão estar adaptadas de forma que o corpo possa trabalhar na vertical sem precisar fletir o tronco e a elevação membro superior (GARBIN et al., 2008).

Segundo Deliberato (2002) uma das formas de prevenção dos DORT's nos profissionais, (cirurgiões-dentistas, digitadores, fisioterapeutas, motoristas, entre outros) é a Cinesioterapia Laboral (CL), que tem como objetivos: melhorar a postura, aumentar a resistência a fadiga, melhorar os movimentos executados, promover o bem - estar geral, diminuir o estresse ocupacional e combater o sedentarismo, onde podem ser aplicadas antes, durante e depois da rotina de trabalho.

Quando é aplicada antes da rotina de trabalho ela é chamada de CL Preparatória, com atividades de aquecimento e alongamento para que o corpo e a mente se preparem para receber a carga de trabalho; a CL Compensatória ou de Pausa é utilizada no meio do expediente de trabalho com atividades de alongamento, mobilização, atividades lúdicas, massagens, com objetivo de quebrar a rotina e a monotonia; e por último a CL do tipo Relaxante com atividades de alongamento, exercícios respiratórios, Pilates, meditação, relaxamento, integração com o grupo, com o principal objetivo de relaxamento depois da rotina de trabalho.

\section{Distúrbios Osteomusculares Relacionados Ao Trabalho (Dort) E A Odontologia}

O capítulo relata sobre a relação dos cirurgiões-dentistas com o distúrbio osteomuscular relacionado ao trabalho, como também, os principais sinais e sintomas encontrados entre os profissionais. Finalizando o capítulo veremos quais os principais DORT's que podem acometê-los e os níveis de dor que os mesmos podem sentir. 


\section{Histórico LER/DORT}

Quando buscamos a manutenção de um estado de equilíbrio do organismo, que não é mais possível, surgem as adaptações que se não forem organizadas satisfatoriamente, aumentam os riscos de aparecimento dos distúrbios psicofísico relacionados ao trabalho, estes distúrbios foram originalmente chamados de Lesões por Esforços Repetitivos (LER) (DELIBERATO, 2002).

De acordo com Deliberato (2002) as LER's representam um fenômeno mundial, e por a sua nomenclatura varia de país a país, a Organização Mundial de Saúde (OMS), recomendou a unificação das nomenclaturas, hoje citada entre os países com o termo de Wort Related Musculoskeletal Disorders, traduzida no Brasil como Distúrbios Osteomuscular Relacionado ao Trabalho (DORT).

O DORT é um fenômeno que envolve a permanência ao trabalho, onde se caracteriza pela ocorrência de vários sinais e sintomas, no qual, estão diretamente relacionados com as lesões de tendões, nervos, músculos, estrutura de suporte entre outros, sendo mais comum em membros superiores e na coluna vertebral. O DORT está entre as causas mais frequentes de incapacidade laboral, temporária ou permanente. Tendo como resultado a super utilização das estruturas anatômicas do sistema osteomuscular e da falta de tempo para uma ideal recuperação (RASSIA, 2004).

De acordo com Barbosa (2009) há três definições sobre o DORT que são consideradas no cenário médico, principalmente por se tratar de definições legalmente institucionalizadas no caso da aplicação diante ao INSS.

Os DORT's como sendo uns transtornos funcionais, mecânico e de lesões de músculo e/ou tendões e/ou fáscias e/ou nervos e/ou de bolsas articulares e pontas de ósseas (COUTO apud BARBOSA, 2009).

Oliveira (1991) definiu como sendo uma desordem neuro-músculo-tendinosas que podem ser de origem ocupacional, atingindo os membros superiores, escápula e pescoço sendo causados pelo uso de movimentos repetitivos e pela força dos grupos musculares ou manutenção de postura imprópria.

A Norma Técnica para Avaliação da Incapacidade (1993) relata que os DORT’s é uma inflamação que envolve os tecidos sinoviais, tendões, fáscias, músculos, ligamentos e nervos, cuja a causa pode ser de origem ocupacionais, mesmo sendo associada a outras patologias.

Segundo Deliberato (2002) dividiu os principais DORT's em dois grupos onde a fisiopatologia do DORT influenciará em cada grupo, são elas:

1. Neuropatias compressivas: onde o nervo será comprimido por alguma estrutura por onde trafega, na grande maioria acometem os membros superiores, dentro deste grupo podemos destacar a síndrome do desfiladeiro torácico, síndrome do supinador, síndrome do pronador redondo, síndrome do túnel do carpo, síndrome do interósseo anterior, síndrome do canal cubital e síndrome do canal de Guyton. 
2. Tendinites e tenossinovites: são doenças inflamatórias que comprometem as bainhas tendíneas e os tendões, decorrentes das exigências trabalhistas, dentro deste grupo podem destacar a doença de DeQuervain, dedo em gatilho, epicondilite lateral, epitrocleíte, tendinite biciptal, tendinite do supra-espinhoso, tendinite distal do bíceps e tenossinovite do braquiorradial.

Além destes grupos encontramos os seguintes DORT's: cistos sinoviais, distrofia simpáticoreflexa, síndrome miofascial e contratura da fáscia palmar.

Quando o profissional de Odontologia adota em suas atividades diárias uma má postura, ele está predisposto ao aparecimento das lesões músculo-esqueléticas, essas lesões, pode ser incômodas e, até mesmo incapacitantes. Quando o posto de trabalho está mal projetado ergonomicamente, o profissional tende a utilizar as posturas erradas, predispondo às lesões que acometem as estruturas músculo-esqueléticas (RIO apud BARBOSA et al., 2004).

$\mathrm{Na}$ rotina de trabalho dos cirurgiões-dentistas há uma grande utilização dos membros superiores principalmente das mãos, que sofrem com as repetitividades de movimentos em um mesmo padrão, como também, pela compressão mecânica das estruturas localizadas nas regiões e muitas vezes devido ao trabalho ser sob pressão temporária (DURANTE; VIELA apud BARBOSA et al., 2004).

\section{Os Sinais e Sintomas}

Segundo o Ministério da Saúde (2002) as manifestações mais comuns encontrados nos DORT's são: dor, formigamento, adormecimento e queimação do membro ou local especifico, podem estarem predispostos com edemas, diminuição da sensibilidade, fraqueza, frio ou calor, atrofia de musculatura específica e perda da capacidade funcional.

De acordo com Oliveira apud Mendes (2008) o diagnóstico do DORT é basicamente analisado pelos dados clínicos, exames físicos e complementares e pela história clínica laborativa, devido aos sinais e sintomas apresentarem de forma inespecíficas e indefinidas, muitas vezes são ignorados, justificando assim o aparecimento de outras lesões.

Entre as principais DORT's que acometem os cirurgiões-dentistas destacam-se:

- Cervicobraquialgia: É a presença de dor cervical que ocorre quando a sede da discopatia é póstero-lateral, ocorre a protrusão do canal vertebral produzindo cervicalgia por irritação do plexo sensitivo raquidiano e braquialgia pelo contato com a raiz. Frequentemente, o quadro clínico das cervicobraquialgias é unilateral, sendo que a dor inicia-se na região cervical baixa e se irradia para o membro superior, com topografia radicular usualmente associada às parestesias de um ou mais dedos (PRZYVARA; REZENDE, 2009). 
Segundo Maehler (2003), a cervicobraquialgia é uma desordem orgânica e funcional que é provocada pelo trabalho repetitivo, aumentando a carga muscular estática, secundária a postos de trabalho inadequados, devido os CD’s realizarem movimentos de flexão cervical, lateralização e inclinação, a cervicobraquialgia é muito comum nesses profissionais. O indivíduo lesionado sente dor na região cervical e ombros, cefaléia, fraqueza e fadiga muscular, além de parestesias e tontura. Apresenta-se com contratura da musculatura cérvico-torácica com "nódulos" (pontos gatilhos) dor a palpação, limitação da movimentação cervical e redução da lordose cervical e ombros deprimidos.

- Síndrome do túnel do carpo: É considerada como uma neuropatia de maior incidência. Ela consiste na compressão do nervo mediano e nas demais estruturas que passa pelo túnel do carpo. Entre os principais sinais e sintomas temos: a dor noturna com queimação, atrofia tênar e parestesia. Tendo como consequiência, limitação de atividade e incapacidade para o trabalho (KAROLCZAK; VAZ; FREITAS; MERLO, 2005).

Segundo Zuffo (2006) os CD’s no seu ambiente de trabalho realizam movimentos repetitivos de flexão e extensão do punho, ocasionando parestesia nas mãos, dificultando assim, a realização de pinça e apreensão.

- Bursites: Caracterizam-se pela ocorrência de processo inflamatório das bursas, ou seja, das pequenas bolsas de parede finas, constituídas de fibras colágenas e revestidas de membrana sinovial localizadas nas proximidades das inserções tendíneas e articulações. As bursites localizam-se mais freqüentemente nos ombros e causam dor regional, principalmente durante a realização de certos movimentos como abdução, rotação externa e elevação do membro superior. Quando o tratamento não é adequado, a dor irradia-se para a região escapular ou braços, gerando incapacidade funcional, que culmina com a instalação do "ombro congelado" (capsulite adesiva) ou da síndrome ombro-mão (distrofia simpático-reflexa) (LODUCA et al., 2007).

Os profissionais CD’s ao utilizar o membro superior para realização de certos procedimentos longos e repetitivos podem apresentam inflamações nessas bursas, tendo como consequências dores e limitações dos movimentos.

- Síndrome do desfiladeiro torácico. Ocorre devido a uma compressão do feixe neurovascular na região do tórax, mais conhecida como desfiladeiro, formado pela clavícula, primeira costela, músculo escaleno médio e anterior e fáscia. Tem como sinais e sintomas de parestesias e dor irradiada para os membros superiores (MMSS), principalmente durante a 
elevação de um deles, pode também ocorrer alterações neurovegetativas (temperatura, cor, sudorese), hipoestesia, déficits de força e amiotrofia nos MMSS (CALDEIRA, 1999).

Segundo Zuffo (2006), uma boa parte do tempo de atendimento, o profissional utiliza o membro superior de forma não ergonômica, utilizando flexão lateral do pescoço e elevação do ombro, ocorrendo, assim, uma compressão sobre o ombro, repercutindo em sensação dolorosa no membro superior.

- Epicondilite lateral do cotovelo: Também conhecida como "cotovelo do tenista" é uma síndrome inflamatória dolorosa localizada na região do epicôndilo lateral (extensores do carpo) e nas regiões proximais dos músculos flexores, parte óssea mais proeminente no aspecto lateral do cotovelo, sendo sítio de origem dos músculos supinador do antebraço, extensores do punho e dos dedos (DELIBERATO, 2002).

De acordo com Machado (2004) essa síndrome ocorre devido ao esforço excessivo de extensão ou flexão brusca do punho utilizado diariamente. A dor localiza-se no cotovelo, mas pode se irradiar para o ombro ou para a mão, prejudicando assim a produtividade dos demais profissionais.

- Tenossinovite estenosante de Quervain ou síndrome de Quervain: É caracterizada pela dor aguda ou crônica na parte superior do polegar, perto do punho. A dor diminui os movimentos funcionais das mãos principalmente na ação de garra ou pinça (CHAMBRIARD et al., 1998).

De acordo com Zuffo (2006), há uma grande sobre carga os movimentos de pinças finas e grossas pelo polegar, ocasionando dores e sensação de peso no local lesionado.

- Tendinite: É uma inflamação que envolve os tendões, podendo haver ou não uma degeneração de suas fibras (DELIBERATO, 2002).

A tendinite é encontrada com facilidade nestes profissionais, pois os mesmos utilizam com frequência a posição de flexão de punho, ao realizar procedimentos de extrações e restaurações, ocasionando dores e queixas de parestesia no membro. 


\section{A Dor}

Segundo Porto (2004) a dor é considerada uma experiência sensorial e emocional que se torna desagradável quando é associada a uma lesão tissular potencial ou real, ou até mesmo quando não há nenhum tipo de lesão.

O principal mecanismo de proteção do corpo é a dor, na qual ocorre quando o indivíduo lesiona alguma estrutura, fazendo com que o mesmo reaja a esses estímulos dolorosos. Existem dois tipos de dor: a rápida ou aguda que é sentida durante segundos depois do estímulo doloroso tenha sido aplicado; e a dor lenta ou crônica que é de forma tardia, que pode ter duração entre segundos, minutos ou dias. A dor pode ser diferenciada entre três classificações de estímulos entre elas: a mecânica, química e a térmica (GUYTON; HALL, 2002).

O Ministério da Previdência Social, através da Norma Técnica para Avaliação da Incapacidade (1993) relata os estágios evolutivos dos DORT's em quatro graus:

Grau I: Presença de desconforto e sensação de peso no membro lesionado. A dor pode vim espontânea e localizada nos membros superiores e na cintura escapular, pode se apresentar em forma de pontadas que geralmente aparecem durante as atividades do trabalho, mas não interferem na produtividade. Os sinais clínicos estão ausentes e o prognóstico é considerado bom;

Grau II: A dor é mais persistente e intensa, aparece durante a jornada de trabalho. É tolerável, na qual, permite o desempenho da atividade profissional, mas já se tem uma redução significante da produção nos períodos de exacerbação, a dor apresenta mais localizada e pode estar acompanhada de formigamento e calor e leves perdas da sensibilidade. A recuperação é mais demorada, mesmo ao repouso a dor pode aparecer fora do ambiente de trabalho. Os sinais clínicos podem aparecer ausentes, podem ser observadas pequenas nodulações acompanhando a bainha dos tendões. O prognostico é favorável;

Grau III: A dor é mais persistente, forte e tem irradiação. Com o repouso a dor só aumenta, existindo pontos dolorosos mesmo fora do ambiente de trabalho, a dor costuma aparecer a noite. $\mathrm{O}$ indivíduo tem perda de força muscular e parestesias. Nesta a produção decai. Os principais sinais clínicos são: edema, hipertonia muscular, alteração da sensibilidade (palidez, hiperemia e sudorese). Ao tentar realizar os movimentos o grupo muscular acometido reage com dor, nessa etapa a volta da atividade é mais problemática. O prognóstico é reservado;

Grau IV: A dor apresenta com maior intensidade e muitas vezes insuportável, levando ao individuo intenso sofrimento. Ao tentar realizar os movimentos a dor estendida para todo o membro. Nessa fase é constante a perda da força muscular e do controle dos movimentos, o edema é frequente, há presença de atrofias nos dedos, atribuídas aos desusos. A capacidade do trabalho é nula e a invalidez é caracterizada pela impossibilidade da produção do trabalhador. Nesse estágio são comuns as alterações psicológicas. 
Id on Line Revista Multidisciplinar e de Psicologia

Id on Line Multidisciplinary and Psychology Journal

\section{Análise dos Resultados e Discussão}

A amostra foi composta por cirurgiões-dentistas $(n=25)$ atuantes e legalizados no Conselho Regional de Odontologia (CRO-CE). Dentre os profissionais (9) eram do sexo feminino e (16) do sexo masculino.

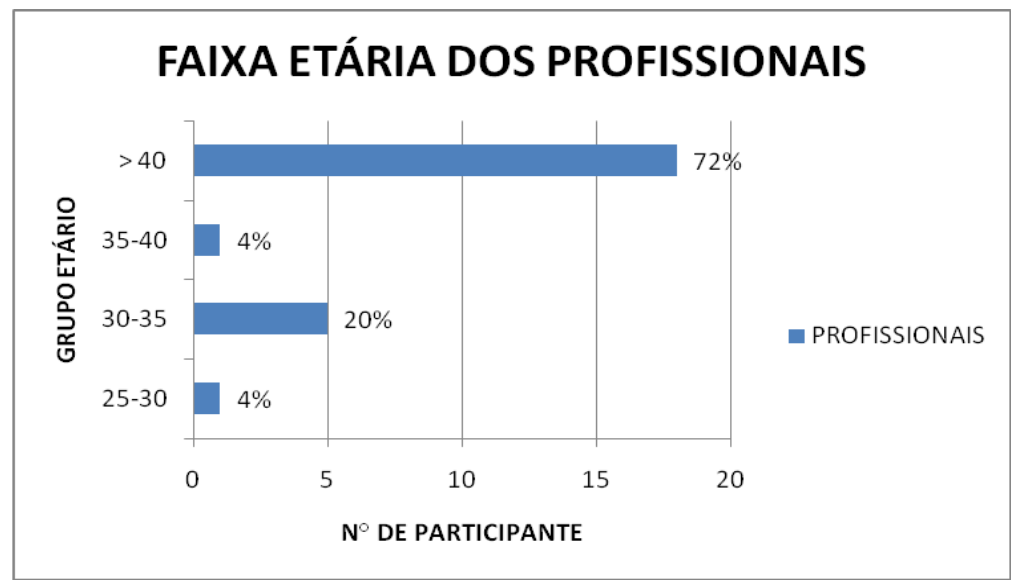

Gráfico 01 - Distribuição da faixa etária dos profissionais.

Fonte: Pesquisa Direta. Barbalha.2009.

Os participantes apresentaram faixa etária maior que 40 anos (72\%). Em seguida 30 a 35 anos (20\%), e por último entre 25 a 30 anos (4\%), 35 a 40 anos (4\%).

Segundo Oliveira (1998) a idade relativa onde há mais freqüência dos Distúrbios Osteomusculares Relacionados ao Trabalho é no período da idade produtiva que está entre 29 e 35 anos.

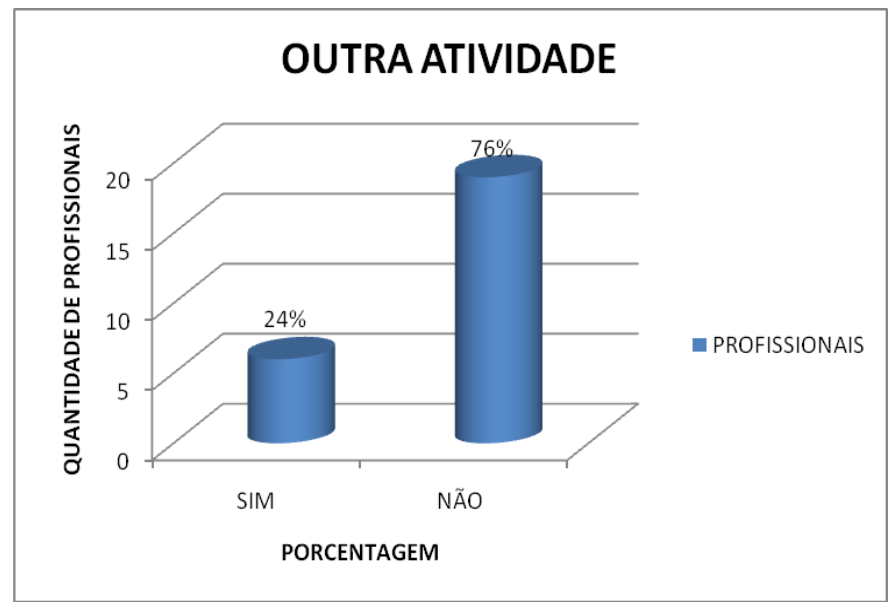

Gráfico 02 - Realização de outra atividade ocupacional. Fonte: Pesquisa Direta. Barbalha.2009. 
Id on Line Revista Multidisciplinar e de Psicologia

Id on Line Multidisciplinary and Psychology Journal

Entre os profissionais $76 \%$ relatou não realizarem outra atividade ocupacional além da Odontologia e $24 \%$ afirmaram desenvolver outra atividade. Este dado ganha importância quando sabemos que a maioria dos entrevistados trabalha exclusivamente como CD's, desta forma podemos afirmar que as dores osteomusculares referidas dos entrevistados estão ligadas apenas ao trabalho de CD's que exercem.

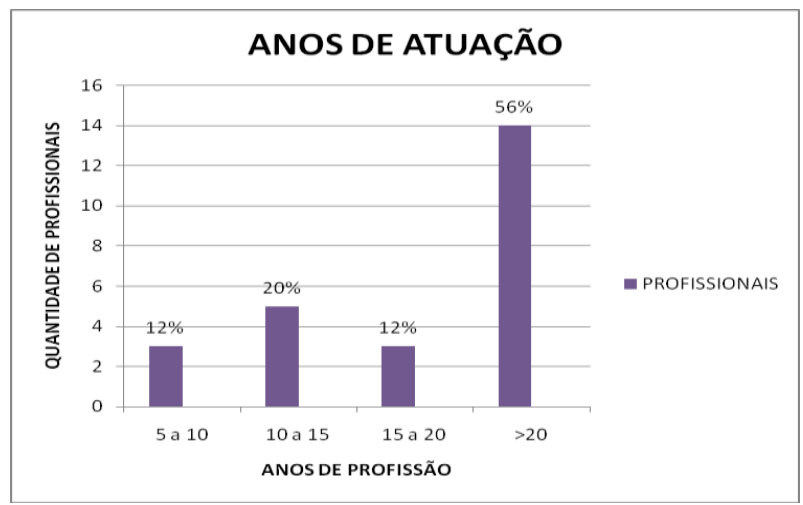

Gráfico 03 - Distribuição dos anos de atuação.

Fonte: Pesquisa Direta. Barbalha.2009.

A maior prevalência foram aqueles com mais de 20 anos de atuação (56\%), em seguida aqueles com variação de idade entre 10 a 15 anos (20\%), 5 a 10 anos foram encontrados (12\%), e 15 a $20 \operatorname{anos}(12 \%)$.

No estudo de Regis Filho et al. (2006) ele observou que a Odontologia é uma profissão que obriga os CD's utilizarem na execução das tarefas o mesmo padrão de movimento, frequentemente com repetitividade, compressão mecânica das estruturas, assumindo muitas vezes posturas incorretas e na maioria dos casos utilizando força excessiva, o fato de trabalhar muitos anos e consequentemente várias horas em vários locais, aumentando a probabilidade de desenvolvimento de lesões osteomusculares.

Em relação às distribuições dos horários de atendimentos dos profissionais podem-se observar no gráfico 04 os principais turnos de trabalho. 


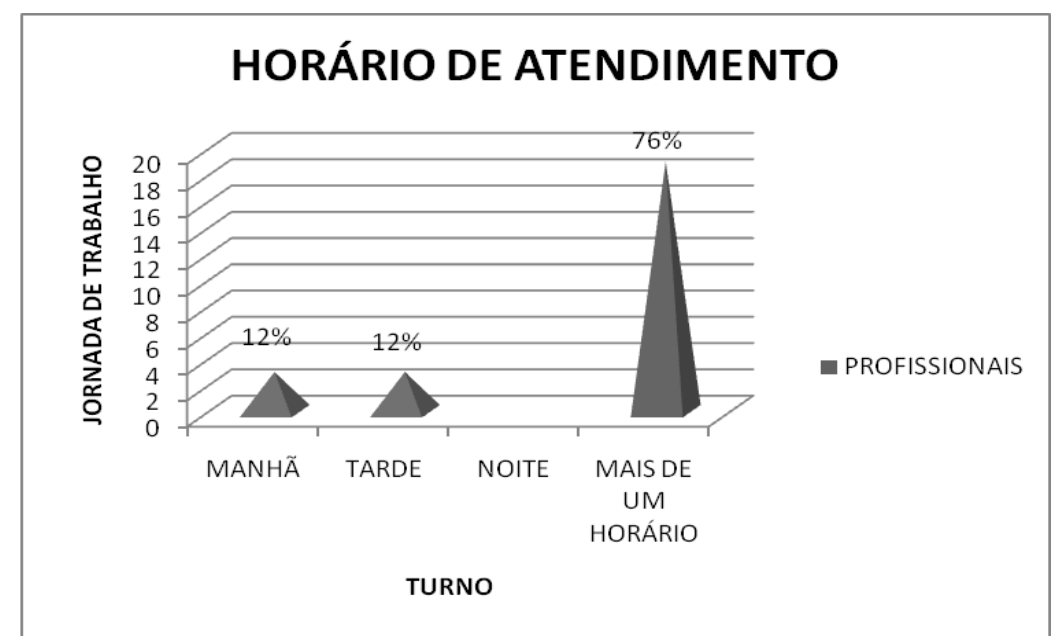

Gráfico 04- Distribuição dos horários de atendimento Fonte: Pesquisa Direta. Barbalha.2009.

Os dados encontrados causam preocupação, visto que a maioria dos profissionais trabalhava mais de um turno (76\%), em seguida (12\%) dos Cirurgiões-Dentistas atendiam no período da manhã e (12\%) no período da tarde.

De acordo com Mota (2009) no mundo atual a prática de trabalhar mais de um horário tornouse rotina, pois vários profissionais da área da saúde trabalham mais de um horário, inclusive o cirurgião-dentista. A carga horária de trabalho é um fator determinante para as principais sintomatologias relacionadas ao trabalho: o cansaço muscular, o movimento repetitivo, a dor, o cansaço mental estão presentes para aqueles que trabalham ultrapassando seus limites físicos e mentais, o dentista está inserido nesse grupo.

Em relação à quantidade de pacientes atendidos diariamente, podemos observar os valores encontrados no gráfico 05 .

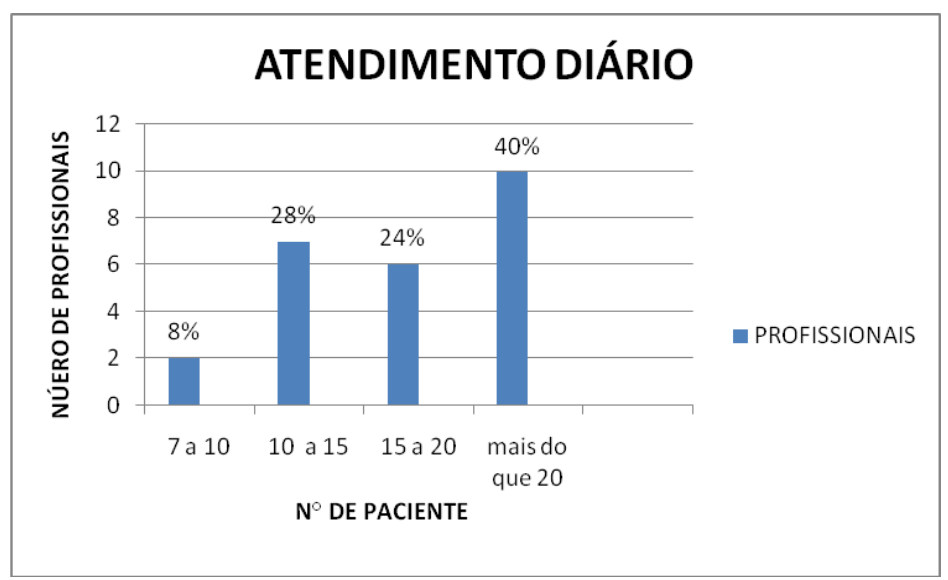

Gráfico 05 - Distribuição da quantidade de pacientes diários atendido pelos profissionais.

Fonte: Pesquisa Direta. Barbalha.2009. 
Entre os atendimentos diários, (40\%) dos entrevistados afirmaram atender mais de 20 pacientes, (28\%) que atendiam de 10 a 15 pacientes, (24\%) pacientes de 15 a 20 e (8\%) de 7 a 10 pacientes.

De acordo com Baú (2002) refere que a pausa entre os atendimentos odontológicos é um mecanismo fisiológico de compensação e de prevenção contra a fadiga crônica. Sendo que certas pausas pequenas permitirá ao individuo mudar de posição, se levantar, caminhar, fazendo com que haja o alongamento de algumas estruturas e melhorando a oxigenação dos tecidos.

No quesito em que os entrevistados relatavam quais os procedimentos que produzem algias, podemos observar os resultados no gráfico 06.

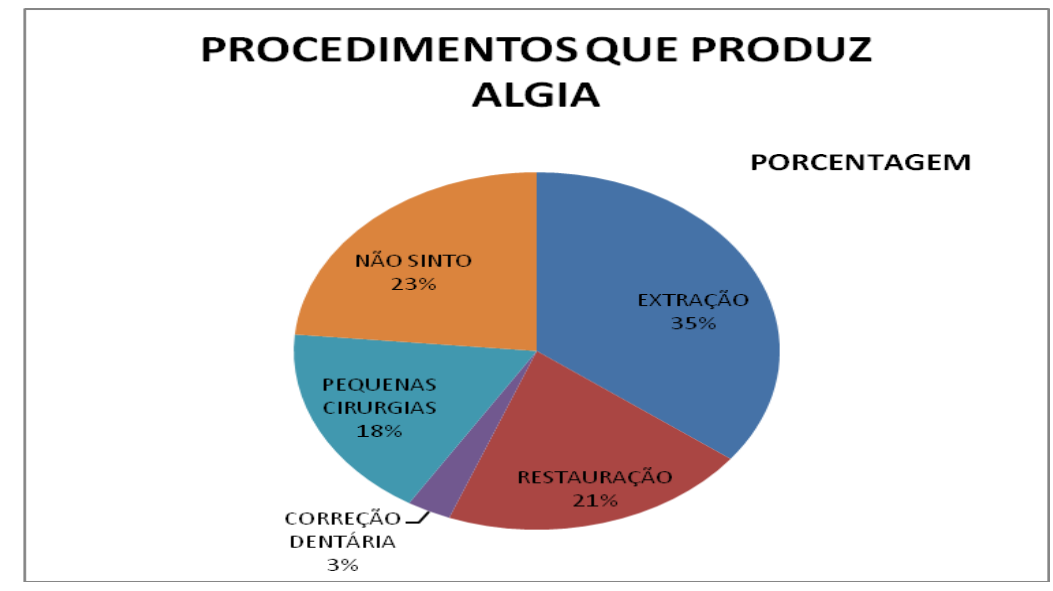

Gráfico 06 - Distribuição dos procedimentos que produzem algias.

Fonte: Pesquisa Direta. Barbalha.2009.

Dentre os procedimentos que produzem algias observamos que a extração equivale a um percentual de (35\%), seguido pela restauração (21\%), de (18\%) nas pequenas cirurgias e (3\%) nas correções dentárias, enquanto que (23\%) afirmaram não sentir nenhum tipo de algias.

Em relação quanto às principais patologias que os cirurgiões buscaram assistência médica podemos observar os resultados na tabela 01 .

Tabela 01 - Principais patologias relatadas ente os cirurgiões-dentistas.

\begin{tabular}{|c|c|c|c|c|c|c|c|c|}
\hline & Tendinite & $\begin{array}{c}\text { Cervico- } \\
\text { braquialgia }\end{array}$ & $\begin{array}{c}\text { Ombro } \\
\text { Doloroso }\end{array}$ & $\begin{array}{c}\text { Síndrome do } \\
\text { Desfiladeiro } \\
\text { Torácico }\end{array}$ & $\begin{array}{c}\text { Epicon- } \\
\text { dilite }\end{array}$ & $\begin{array}{c}\text { Síndrome do } \\
\text { Túnel do } \\
\text { Carpo }\end{array}$ & $\begin{array}{c}\text { Lomboci- } \\
\text { atalgia }\end{array}$ & $\begin{array}{c}\text { Hérnia } \\
\text { de Disco }\end{array}$ \\
\hline$\%$ & 20 & 0 & 12 & 4 & 0 & 0 & 4 & 4 \\
\hline
\end{tabular}

Fonte: Pesquisa Direta. Barbalha.2009. 
O estudo concorda com a pesquisa de Mendes (2008) o autor relata em seu estudo que a tendinite é a lesão mais comum encontrada, entre as patologias mais relatadas pelos profissionais da área de Odontologia.

A tabela 02 relata as regiões com maiores incidências de dores encontradas entre os entrevistados.

Tabela 02- Incidência dos sinais e sintomas

\begin{tabular}{|c|l|l|l|l|l|l|l|l|l|}
\hline $\begin{array}{l}\text { Sinais e } \\
\text { Sintomas } \\
\text { de DORT }\end{array}$ & $\begin{array}{l}\text { Região } \\
\text { Cervi- } \\
\text { cal }\end{array}$ & $\begin{array}{l}\text { Om- } \\
\text { bro }\end{array}$ & $\begin{array}{l}\text { Bra- } \\
\text { ço }\end{array}$ & $\begin{array}{l}\text { Cotove- } \\
\text { lo }\end{array}$ & $\begin{array}{l}\text { Antebra- } \\
\text { ço }\end{array}$ & $\begin{array}{l}\text { Punhos, } \\
\text { mãos } \\
\text { dedos }\end{array}$ & $\begin{array}{l}\text { Dor- } \\
\text { sal }\end{array}$ & $\begin{array}{l}\text { Lom- } \\
\text { bar }\end{array}$ & $\begin{array}{l}\text { Membros } \\
\text { inferiores }\end{array}$ \\
\hline Naro & $30 \%$ & $28 \%$ & $56 \%$ & $80 \%$ & $72 \%$ & $24 \%$ & $28 \%$ & $36 \%$ & $48 \%$ \\
\hline $\begin{array}{c}\text { Comente } \\
\text { Frequência }\end{array}$ & $38 \%$ & $28 \%$ & $36 \%$ & $12 \%$ & $24 \%$ & $32 \%$ & $32 \%$ & $28 \%$ & $16 \%$ \\
\hline Sempre & O\% & $40 \%$ & $8 \%$ & $8 \%$ & $4 \%$ & $40 \%$ & $36 \%$ & $36 \%$ & $36 \%$ \\
\hline
\end{tabular}

Fonte: Pesquisa Direta. Barbalha.2009.

Um dado preocupante encontrado na pesquisa diz respeito que $40 \%$ dos entrevistados apresentavam sinais e sintomas de DORT com frequência nos membros superiores e $36 \%$ em coluna dorsal, lombar e membros inferiores.

No estudo de Mendes (2008) a região mais indicada pelos dentistas foi a região dos ombros (34\%), seguindo-se a zona cervical (21\%) e, posteriormente a coluna lombar (15\%), a região dorsal, mãos e punhos foram atribuídas às porcentagens de $(12 \%),(9 \%)$ e $(6 \%)$, respectivamente. Sendo que os cotovelos apenas referem (3\%). Na maioria dos estudos entre os CD's a região cervical e lombar atinge valores superiores aos referidos para a região do ombro.

Já no estudo realizado por Koltiarenko (2005) dentre as áreas mais envolvidas nos sintomas osteomusculares, a coluna cervical com $(69,93 \%)$, os ombros com $(64,72 \%)$, a coluna lombar com $(62,50 \%),(51,97 \%)$ para punhos e mãos, para os braços $(50 \%)$, para a coluna torácica $(38,82 \%)$, antebraços com $(26,32 \%)$ e finalmente os cotovelos com $(18,42 \%)$. O autor ainda relata que a região anatômica mais indicada com frequência, que apresentava sintomatologia de origem músculoesquelética foi a da coluna cervical, seguida pelos ombros e coluna lombar, já a região que menos referiu sintomatologia foi a dos cotovelos com a primeira indicação de nunca ou raramente apresentar sintomas e na última colocação quando da presença deles. 


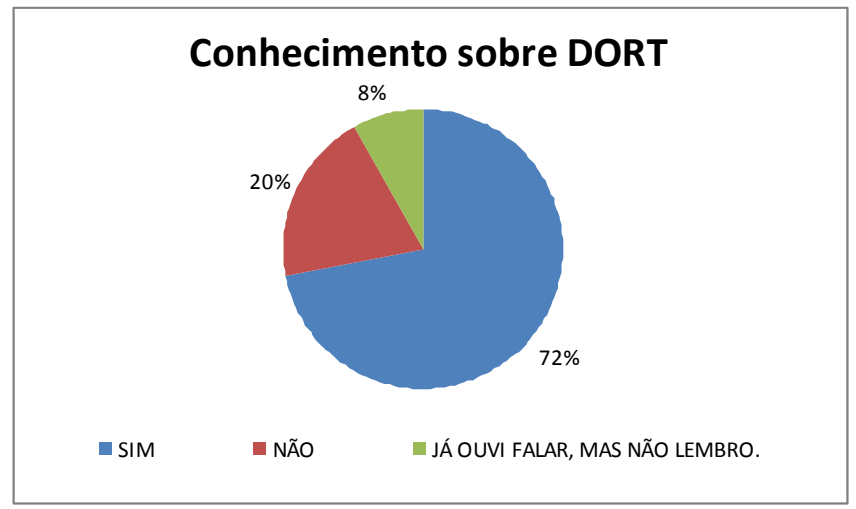

Gráfico 07 - Distribuição dos conhecimentos dos profissionais a respeito do DORT. Fonte: Pesquisa Direta. Barbalha.2009.

Entre os entrevistados (72\%) relataram ter algum conhecimento a respeito do DORT, $(20 \%)$ afirmam não conhecer o DORT.

De acordo com Michellin et al. (2000) índices tão elevados de cirurgiões-dentistas com dores decorrentes de DORT's estão relacionados ao fato destes profissionais, em sua maioria, não darem a devida importância ao uso de métodos para prevenir este tipo de lesão, apesar de terem conhecimento sobre os riscos e implicações a que estão sujeitos.

Quanto as condições ergonômicas do ambiente de trabalho seus resultados podem ser observados no gráfico 08 .

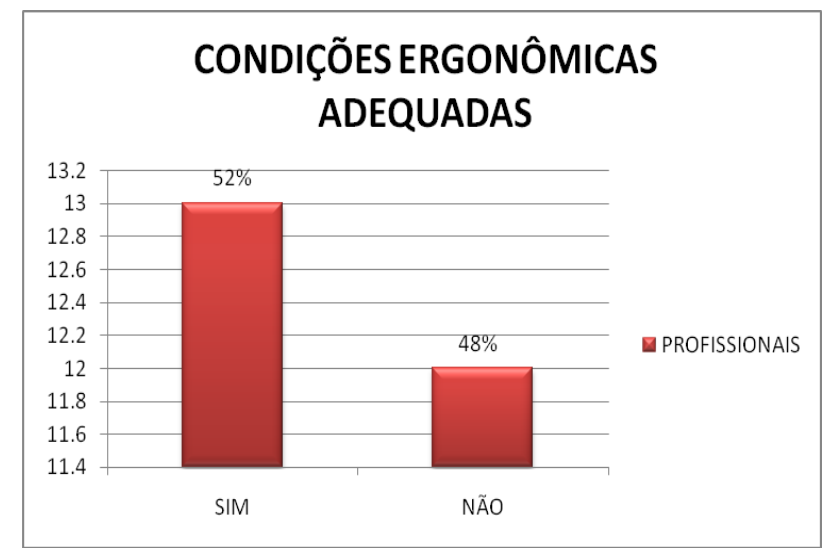

Gráfico 08 - Distribuição da presença de um ambiente ergonomicamente adequado. Fonte: Pesquisa Direta. Barbalha.2009.

Nas condições ergonômicas do posto de trabalho a maioria dos entrevistados, (52\%) relataram que seu posto de trabalho está satisfatoriamente adequado enquanto que (48\%) acham que está ergonomicamente inadequado.

Segundo Barbosa et al. (2004) dentre outros fatores relacionados a grande incidência de DORT’s nesta categoria profissional está a utilização de equipamentos ergonomicamente inadequados, 
que resultam na adoção de posturas impróprias durante o atendimento. Tais posturas além de provocarem distúrbios na coluna vertebral poderão afetar o sistema cardiovascular e respiratório.

No estudo de Regis Filho et al. ( 2004) a inadequação ergonômica é presente tanto no mobiliário, como, por exemplo, o mocho com o encosto inadequado, quanto nos equipamentos odontológicos que, além de estarem mal distribuídos pelo consultório, são desenvolvidos para realizar os procedimentos odontológicos propriamente ditos, sem haver uma preocupação de que haja um ajuste ergonômico deste instrumento ao cirurgião-dentista, o que pode levar ao desenvolvimento de patologias do sistema músculo-esquelético, às quais provocam a incapacitação para o trabalho.

O gráfico mostra o percentual de realização do alongamento antes dos procedimentos clínicos.

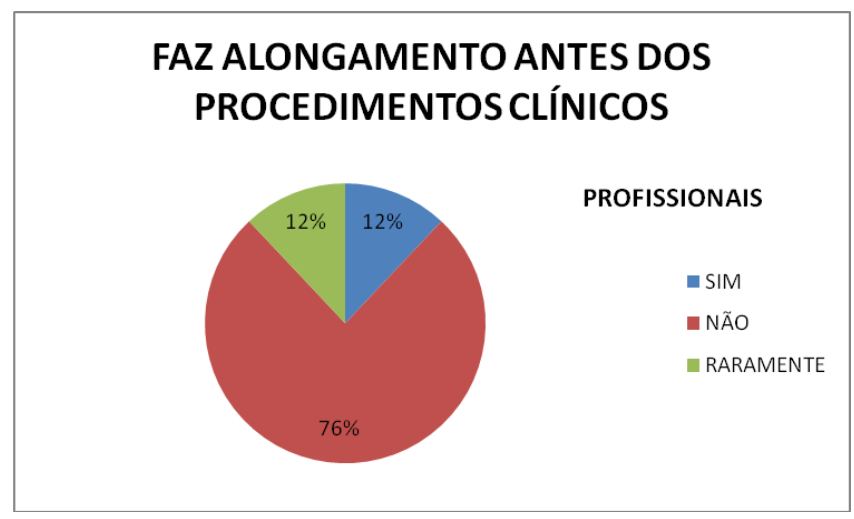

Gráfico 09 - Distribuição dos profissionais com o hábito de alongamento.

Fonte: Pesquisa Direta. Barbalha.2009

Em relação ao hábito de alongamento o resultado não foi satisfatório, pois (76\%) dos entrevistados relataram não realizar a prática de alongamento antes dos atendimentos odontológicos, (12\%) realizam os alongamentos e com a mesma porcentagem (12\%) realizam raramente a prática de alongamento.

De acordo com Pinto (2003) o alongamento é uma forma de trabalho que visa a manutenção dos níveis de flexibilidade obtidos e a realização dos movimentos de amplitude normal com o mínimo de restrição física possível. É uma atividade simples, suave, tranqüila, que proporciona grande relaxamento e bem-estar. Praticado corretamente, pode evitar muitos problemas relacionados ao trabalho, com a vantagem de que pode ser realizado em quase todos os lugares e a qualquer hora, não exigindo nenhum equipamento especial, ou seja, o indivíduo pode alongar-se periodicamente no decorrer do dia.

O gráfico 10 mostra a prática de atividade física na sua vida cotidiana. 


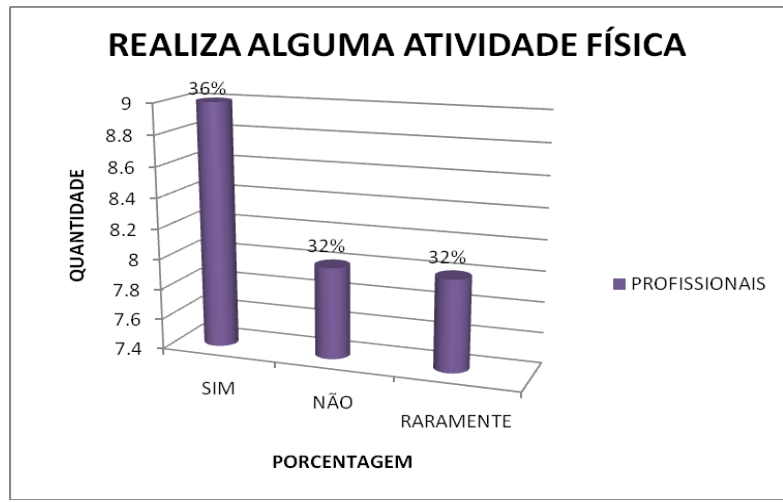

Gráfico 10 - Percentual de realização de atividade física. Fonte: Pesquisa Direta. Barbalha.2009.

Os resultados obtidos são satisfatórios, visto que a maioria dos entrevistados (36\%) afirmou praticar alguma atividade física, (32\%) não faz nenhum tipo de atividade física ou práticam atividade raramente.

Segundo Rucker e Sunele (2002) alguns fatores contribuem para o aumento de sintomas osteomusculares como por exemplos: a questão do padrão de vida dos profissionais, o sedentarismo, os desvios irregulares da coluna vertebral, problemas visuais e oftalmológicos, entre outros. Realizar atividades físicas moderadamente diminui a probabilidade de apresentarem sintomas relacionados aos DORT's.

De acordo com Michelin et al. (2000) quando se tem um planejamento cuidadoso em relação ao afazeres clínicos, a execução de atividades físicas diárias, a precaução quanto a postura, entre outros, melhora mais a saúde do profissional e seu desempenho em suas atividades físicas.

\section{Conclusões}

De acordo com os dados coletados pôde-se verificar que a média de idade dos profissionais é superior a 40 anos $(72 \%)$.

Em relação à realização de outras atividades ocupacionais (76\%) relatou não praticá-las.

Dentre os anos de atuação (56\%) atua mais de 20 anos e (76\%) trabalha mais de um turno, (40\%) atendendo mais de 20 pacientes diariamente.

Dentre os procedimentos clínicos que mais produzem algias a extração obteve a maior incidência (35\%) e das patologias mais frequentes entre os profissionais a tendinite obteve $(20 \%)$.

Entre o conhecimento dos profissionais sobre o DORT (72\%) relataram conhecer o distúrbio, (52\%) afirmaram que seu posto de trabalho está ergonomicamente adequado. 
Id on Line Revista Multidisciplinar e de Psicologia

Id on Line Multidisciplinary and Psychology Journal

Um dado relevante foi sobre o hábito de alongamento, onde (76\%) dos entrevistados não realizam alongamento antes dos procedimentos clínicos e (36\%) pratica alguma atividade física.

$\mathrm{O}$ aparecimento de sinais e sintomas osteomusculares relacionados ao trabalho, foi alarmante, pois $40 \%$ dos entrevistados relataram o aparecimento dos sinais e sintomas osteomusculares com frequência nos membros superiores e $36 \%$ em coluna dorsal, lombar e membros inferiores.

Ao longo do estudo pode-se observar que há uma grande escassez de pesquisas no que diz respeito aos cirurgiões-dentistas. Visto que essa classe vem aumentando o número de afastamentos temporários, devido ao aparecimento dos sinais e sintomas osteomioarticulares, merecendo dessa forma mais pesquisas e estudos referentes à saúde dos profissionais e as principais prevenções que os profissionais devem realizar no dia-a-dia de trabalho.

\section{Referências}

ALMEIDA, E.C. S, VENDÚSCULO, D.M.S, MESTRINER-JUNIOR, W. A conformação da Odontologia enquanto profissão: uma revisão bibliográfica. Rev Brasileira de Odontologia; v.59, n. 6, p.370-373, 2002.

ARAÚJO, A.M; PAULA, M.V.Q. Ler/Dort um grave problema de saúde pública que acomete os cirurgiões-dentistas, 2003. Disponível em: <http://psicologia.esc_joseregio.pt/wpcontet/uploads/2008/10/dentista.pdf> Acesso em: 23 abr. 2009.

BARBOSA et al. Prevalência de Distúrbios Osteomusculares Relacionados ao Trabalho em Cirurgiões-Dentistas de Campina Grande - PB. Rev. Pesq Bras Odontoped Clin Integr, João Pessoa, v. 4, n. 1, p. 19-24, jan./abr. 2004.

BARBOSA, L.G. Fisioterapia Preventiva nos Distúrbios Osteomusculares Relacionados ao Trabalho - DORT's. A Fisioterapia do trabalho aplicado. 2 ed. Rio de Janeiro: Guanabara Koogan, 2009.

BAÚ, S. Fisioterapia do trabalho: Ergonomia - Legislação - Reabilitação. 1 ed. Curitiba: Clã da Silva, 2002.

CALDEIRA, F.H., et al. Síndrome do Desfiladeiro Torácico Tipo Neurogênico Verdadeiro. Rev Arq Neuropsiquiatr, v.57, n.3, p.659-665,1999.

CARVALHO, G.P. História da Odontologia Legal Disponível em:< http://www.carvalho.odo.br/index2.php?option=com_content\&do_pdf=1\&id=124 > Acessado em: 11 set. 2009.

CHAMBRIARD, C.; et al. A reoperação na tenossinovite de De Quervain. Rev., Bras Ortop., v.33, n.2, p128-130, 1998.

CONSELHO REGIONAL DE ODONTOLOGIA DO CEÁRA. Disponível em:< http://www.croce.org.br/portal/ > Acessado em: 11 set. 2009. 
Id on Line Revista Multidisciplinar e de Psicologia

Id on Line Multidisciplinary and Psychology Journal

CODIGO DE ÉTICA, 2006. Disponível em:< http://www.cro-rj.org.br/doc/codigo_etica\%202006.pdf > Acessado em: 08 out. 2009.

DELIBERATO, P. C. P. Fisioterapia preventiva: Fundamentos e aplicações. São Paulo: Manole, 2002.

GARBIN, A.J., et al. Iluminação no consultório odontológico. Rev. Acta Científica Venezolana., v.58, n1, p. 29-32, 2007.

GARBIN, A.J.I., et al. Ergonomia e o cirurgião-dentista: uma avaliação do atendimento clínico usando análise de filmagem. Rev. Odonto. Ciênc., v.23, n.2, p.130-133, 2008.

GUTTON; A.C; HALL. Tratado de fisiologia médica. 10 ed. Rio de Janeiro: Guanabara 2002.

HALL, S. J. Biomecânica básica. 4 ed. Rio de Janeiro: Guanabara, 2005.

JACOB, et al. Anatomia e fisiologia humana. 5 ed. Rio de Janeiro: Guanabara, 1982.

KAPANDJI, I. Fisiologia Articular. 5 ed. Rio de Janeiro: Panamericana, 2000.

KAROLCZAK, A. P. B., et al. Síndrome do Túnel do Carpo. Rev. bras. fisioter. v. 9, n. 2, p.117-122, 2005.

KILBOM, B. Musculoskeletal Disorders in the workplace. Proceedings of the 12th Triennial Congress of the International Ergonomics Association. Toronto, 1994.

KOLTIARENKO, A. PREVALÊNCIA DE DISTÚRBIOS OSTEOMUSCULARES NOS

CIRURGIÕES DENTISTAS DO MEIO OESTE CATARINENSE, 2005. Joaçaba, SC. Universidade do Oeste de Santa Catarina - UNOESC, 2005

KROEMER, K. H. E; GRANDJEAN, E. Manual de Ergonomia: adaptando o trabalho ao homem. 5 ed. Porto Alegre: Bookman, 2005.

LACERDA, A.; et al. Nível de pressão sonora de um consultório odontológico: uma análise ergonômica. Rev .Ciência e Cultura., v.3, n.26, p.17-24, 2002.

LODUCA, A.; et al. Distúrbios Osteomusculares Relacionados ao Trabalho, 2007. Disponível em:< http://www.centrodeestudosdador.com.br/mat/artDistOst.pdf > Acessado em: 29 set. 2009

MACHADO, A.C.; As Principais L.E.R em Músicos, 2004. Disponível em: <http://www.demac.ufu.br/andrecampos/textos/ler.pdf > Acessado em: 29 set. 2009.

MAEHLER, P. Estudo das Sobrecargas Posturais em Acadêmicos de Odontologia da Universidade Estadual do Oeste do Paraná - Unioeste - Cascavel, Cascavel, PR. Universidade Estadual do Oeste do Paraná, 2003.

MARCONI, M.A.; LAKATOS, E.M. Metodologia Científica. 5 ed. São Paulo: Revista e Aplicação, 2009.

MEDES. N. Estudo da Prevalência de Lesões em Médicos Dentistas da Região do Grande Parto. Análise ergonômica do ambiente do ambiente de trabalho e levantamento de lesões. Parto. Faculdade de Desporto do Porto, 2008.

MICHELIN, C. F; MICHELIN, A. F; LOUREIRO, C. A. Estudo Epidemiológico dos 
Distúrbios Músculoesqueletais e Ergonômicos em Cirurgiões - Dentistas. Rev da

Faculdade de Odontologia da Universidade de Passo Fundo. Passo Fundo, v. 5, n. 2, p.61-67, jul./dez. 2000.

MINISTÉRIO DA PREVIDÊNCIA SOCIAL, $1993 . \quad$ Disponível em: <http://www.previdenciasocial.gov.br/conteudoDinamico.php?id=454> Acessado em: 29 out. 2009.

MINISTÉRIO DA SAÚDE, 2002. Disponível em: <http://dtr2001.saude.gov.br/editora/produtos/livros/genero/livros.htm> Acessado em: 20 set. 2009.

MOORE, K.L.; AGUR, A. M. R. Fundamentos de anatomia clínica. 2 ed. Rio de Janeiro: Guanabara koogan, 2004.

MOTA, C.V.F.S. Avaliação da Incapacidade: Um estudo epidemiológico sobre a prevalência de sinais e sintomas osteomioarticulares em fisioterapeutas de Juazeiro do Norte, Ceará. Juazeiro, CE. Faculdade Leão Sampaio, 2009.

MAESTRINI, K. "Moças e Senhoras Dentistas": formação, titulação e mercado de trabalho nas primeiras décadas da República, 2008.2 Disponível em: <http://www.scielo.br/scielo.php?pid=S010459702008000500005\&script=sci_arttext\&tlng=en > Acessado em: 26 set. 2009.

NUNES, M.F.; FREIRE, M.C.M. Qualidade de vida de cirurgiões-dentistas que atuam em um serviço público. Rev. Saúde Pública., v.40, n.6, p.1019-1026, 2006.

OLIVEIRA R. N; OLIVEIRA O.B, Honorários profissionais: sua importância no contexto do consultório odontológico, 1999. Rev Odontologia e sociedade., v.1, n 1e 2, p.51-54, 1999.

OLIVEIRA, C.D.; Manual prático de LER. 2 ed . Belo Horizonte: Health, 1998.

PEQUINI, S.M.; Origens e Conceituação da Ergonomia, $2005 . \quad$ Disponível em: <http://www.posdesign.com.br/artigos/tese_suzi/Volume\%201/07\%20Cap\%C3\%ADtulo\%203\%20$\% 20$ Origens\%20da\%20Ergonomia.pdf > Acessado em: 10 out. 2009.

PINTO, A.C.C.S. Ginástica Loboral à saúde do Cirúrgiões- Dentistas um estado de caso na secretária municipal de saúde de Florianópolis-SC. Florianópolis-SC. Universidade Federal de Santa Catarina- USFC, 2003.

PORTO, C.C. Exame Clínico para a Prática Médica. 5 ed. São Paulo: Guanabara, 2004.

PREVIDÊNCIA SOCIAL, 1998 Disponível em: <http://www.sato.adm.br/RT/indice_previdência_ social-1998. htm > Acessado em: 23 abr. 2009.

PRZYVARA, L.; REZENDE, M.J.; Tratamento da Cervicobraquialgia através da Técnica de Mobilização $\quad 2009 . \quad$ Neural, 2 Disponível <http://www.fag.edu.br/tcc/2008/Fisioterapia/tratamento_da_cervicobraquialgia_atras_da_tecnica_de_ mobilizacao_neural.pdf > Acessado em: 05 out. 2009.

RASSIA. D. Quando a dor é do Dentista! Custo humano do trabalho de endodontistas e indicadores de Dort. Dissertação. Brasília, DF. Universidade de Brasília. 2004.

REGIS FILHO, G. I; MICHELS, G; SELL, I. Lesões por Esforços Repetitivos em Cirurgiões Dentistas: Aspectos Clínicos - Parte II/III. Jornal Brasileiro de Clínica 
Id on Line Revista Multidisciplinar e de Psicologia

Id on Line Multidisciplinary and Psychology Journal

Odontológica Integrada. n. 44. p. 165-169. mar./abr. 2004.

REGIS FILHO, G. I; MICHELS, G; SELL, I. Lesões por Esforços Repetitivos/ distúrbios osteomusculares relacionados ao trabalho em cirurgiões- dentistas. Rev Bras Epidemial., v.9, n.3, p.346-359, 2006.

ROSENTHAL, E. A História da Odontologia, 1995 Disponível em: <http://www.geocities.com/odontoufpr/historia.html > Acessado em: 07 out. 2009.

RUCKER, L.M.; SUNELL, S. (2002). Ergonomic risk factors associated with clinicalRev. dentristry. Journal of California Dental Association, v. 30, n. 2, p. 139-148, 2002.

RUCKER, L.M.; SUNELL, S. Ergonomic risk factors associated with clinical. Rev. Odontológica Integrada., v.1 n.44. p. 165-9. mar./abr. 2004.

SILVA, A.C.B.; et al. Odontologia do trabalho: avaliação da percepção e conhecimento de formados e profissionais sobre a nova especialidade odontológica. Rev. RFO.,v.12, n.2, p.13-19, 2007.

SILVA, R.H.; SALES, A.P.. Odontologia: um breve histórico. Rev., Odontologia. Clin-cientif., v.6, n.1, p.7-11, 2007.

SOUSA. G.F. Índice de Morbidade Osteomuscular dos Motoristas de Transporte Alternativo do Complexo Crajubar da Região do Cariri. 2009. Monografia (Graduação em Fisioterapia) Faculdade Leão Sampaio, Juazeiro do Norte, CE, 2009.

TORTORA, G.; GRABOWSKI, S.R. O Corpo Humano: Fundamentos de anatomia e fisiologia. 6 ed. Porto Alegre, 2006.

ZUFFO, N. M. Projeto de Intervenção para os desequilíbrios posturais e sintomatologias dolorosas nos cirurgiões dentistas, 2006. Disponível em: <http://www.programapostural.com.br/artigos/projeto_inter2.pdf > Acessado em: 29 set. 2009

Como citar este artigo (Formato ABNT):

LANDIM, L.M.S.; LOPES, C.M.U.; SOUSA, G.F.S.; OLIVEIRA, S.M.; VIEIRA, A.C.C.; BATISTA, H.M.T.; FECHINE, E.M. A. Prevalência dos Sinais e Sintomas Osteomoleculares em Cirurgiões Dentistas. Id on Line Revista Multidisciplinar e de Psicologia, Julho de 2016, vol.10, n.30. p. 50-77, Supl 1. ISSN 1981-1179.

Recebido: $12 / 05 / 2016$.

Aceito: 23/05/2016 